\title{
Factors associated with pacifier use among children of working women with childcare in the workplace
}

Thais Rosa dos Santos ${ }^{(1)}$ Gabriela dos Santos Buccini(2) Luciana Tavares Sebastião(3)

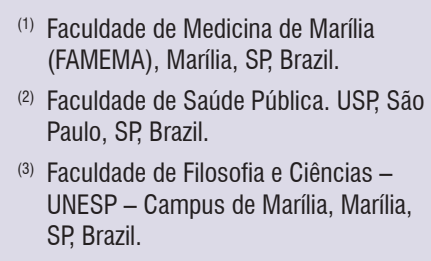
(FAMEMA), Marília, SP, Brazil.

(2) Faculdade de Saúde Pública. USP, São Paulo, SP, Brazil.

(3) Faculdade de Filosofia e Ciências UNESP - Campus de Marília, Marília, SP, Brazil.

Source of support: Ministério da Saúde Residência Multiprofissional

\section{Conflict of interest: Nonexistent}

Received on: January 18, 2017 Accepted on: September 5, 2017

Mailing address: Luciana Tavares Sebastião

Rua Guanás 110 ap. 42 - Montola, Marília, São Paulo, Brasil

CEP: $17502-560$

E-mail: lutsfono@gmail.com

\section{ABSTRACT}

Purpose: to identify the prevalence of pacifier use as well as the reasons for introducing a pacifier and to analyze factors associated with this practice among children of working women with childcare in the workplace.

Methods: a cross-sectional study was conducted with 46 women working at a higher education institution that offered childcare in the workplace; the children were in the age range 2.6 years. Data collection was carried out using a self-report questionnaire filled at home. Reasons for introducing a pacifier were analyzed descriptively; Poisson regression was used in the multiple analysis.

Results: the prevalence of pacifier use was $63 \%$. Most women offered the pacifier after the infant's 16th day of life, in order to calm the baby. In the multiple analysis, higher maternal education was associated with pacifier use.

Conclusion: a high prevalence of pacifier use was observed, as well as early pacifier introduction, among children of working women with childcare in the workplace. With regard to the factors associated with pacifier use in this population, lower maternal education acted as a protective factor against pacifier use.

Keywords: Working Women; Child Health; Pacifier; Speech, Language and Hearing Sciences 


\section{INTRODUCTION}

The implications of pacifier use for child health are widely described in the literature. Pacifier use is associated with a higher incidence of acute otitis media $^{1,2}$, dental malocclusion ${ }^{3,4}$, oral breathing ${ }^{5,6}$, oral motor development alterations ${ }^{7}$, and speech problems ${ }^{8,9}$, and it also has a negative influence on breastfeeding initiation and duration ${ }^{10-14}$. Pacifier use is discouraged by the World Health Organization (WHO), as established in the ninth step of the Baby Friendly Hospital Initiative, which recommends not giving artificial nipples or pacifiers to breastfeeding infants ${ }^{15}$.

In Brazil, a nation-wide survey on breastfeeding prevalence (II Pesquisa Nacional de Prevalência de Amamentação) conducted in all Brazilian capitals and in the Federal District in 2009 found that $42.6 \%$ of the infants younger than 1 year used a pacifier ${ }^{16}$. Using a pacifier is a common habit, influenced by socioeconomic, environmental, and/or cultural factors ${ }^{13,14,17-19}$. Studies on the characteristics of pacifier use point to a more frequent use in boys ${ }^{16,18,19}$, infants with low birth weight ${ }^{16,20}$, infants younger than 6 months ${ }^{19}$, those not breastfed at the maternity ward ${ }^{16}$, and those breastfed according to a predetermined schedule ${ }^{21}$. Among maternal characteristics, higher frequencies have been reported in younger ${ }^{16,17}$ and primiparous ${ }^{16,20}$ mothers, those from a low socioeconomic background ${ }^{19}$, smokers $^{22}$ and those with lower education levels ${ }^{18,23}$. Qualitative studies have related the use of a pacifier with cultural issues, maternal insecurity with breastfeeding, baby cry, and baby behavior ${ }^{13,21,24}$. Mother working outside the home was a determining factor of pacifier use in the Brazilian population investigated in the 2009 survey ${ }^{17}$.

Studies involving working mothers in formal employment have evidenced the need for interventions in the workplace to increase the rates of exclusive breastfeeding and reduce the use of pacifiers ${ }^{25}$. In particular, promoting breastfeeding in the workplace may have benefits for women, for babies, and also for the employer. Despite the lack of information on the impact of having childcare in the workplace on breastfeeding outcomes, this strategy has been considered a key intervention to promote breastfeeding among formally employed women ${ }^{26}$. However, the association between the mother's return to work when childcare is available in the workplace and the use of pacifiers has been little explored in the literature. The objectives of this study were to identify the prevalence of pacifier use and the reasons for introducing a pacifier, and to analyze factors associated with this practice among children of working women with childcare center in the workplace.

\section{METHODS}

All stages of this research study were conducted according to the ethical principles that regulate research involving humans, as described in Resolution no. 466/12 of the Brazilian National Health Council and related legislation. The project was reviewed and approved by the Research Ethics Committee of Faculdade de Medicina de Marília (FAMEMA; protocol no. 1.128.554).

This cross-sectional study was carried out at the childcare centerin the workplace offered by FAMEMA for children of employees, students, and residents of the institution. This child care center has 100 children enrolled, with ages ranging from 4 months to 6 years. The FAMEMA health care complex includes three hospitals, a specialty outpatient unit, and a blood center. All female workers are granted 120 days of maternity leave.

All children enrolled into the childcare center whose mothers worked at the complex were included. No speech/language or anatomo-physiological restrictions were applied. Because one of the aspects under investigation was the enjoyment of rights granted to nursing mothers, the following cases were excluded from the sample: (1) children of undergraduate and graduate professors; (2) children whose fathers, rather than mothers, worked at the complex; and (3) children whose mothers did not work at the complex at the time of the child's birth.

The data collection instrument was specifically developed for this study based on the questionnaire used in the previously mentioned Brazilian nationwide survey on breastfeeding (II Pesquisa Nacional de Prevalência de Amamentação), which included children under 1 year of $\mathrm{life}^{16}$. Some adaptations were made because of the specificity of the present sample. In order to guarantee instrument reliability, a pretest was run at the childcare centerin the workplace offered to employees of another higher education institution in the same municipality. The questionnaire was sent out to be answered at home, along with a letter explaining the study objectives and the free informed consent form.

The following data were collected: pacifier use (yes/ no); among those reporting to use or to have used a pacifier, child age upon pacifier introduction $(\leq 15$ days, $16-30$ days, $31-60$ days, $61-90$ days, $91-120$ 
days, 121-150 days, and $>150$ days), and the reasons for pacifier introduction (open question). The outcome variable "pacifier use" was defined as the child currently using or having used a pacifier at some point in life; analyzing the frequency or duration of pacifier use was beyond the scope of this study.

Other information collected and analyzed were: child sex; low birth weight (yes/no); birth at a Baby-Friendly Hospital (yes/no); breastfeeding within the first hour of life (yes/no);maternal age ( $<35$ years; $\geq 35$ years); maternal education (higher education; secondary education), primiparity (yes/no); being a health professional (yes/no); taking breastfeeding breaks(yes/ no); and child age upon enrollment into the childcare center( $\leq 5.0$ months; 5.1-6.0 months; 6.1-24.0 months). The latter variable was stratified as equal to or less than 5 months, as the institution grants a maternity leave of 120 days, and women usually add to that an additional 30 days of vacation.

The profile of study participants was descriptively analyzed, as was pacifier use (prevalence of pacifier use, age upon introduction, and reasons for introduction). The use of a pacifier was described according to child age upon introduction and child age upon enrollment into the childcare center.

In the multiple analysis of the association between pacifier use and covariates, Poisson regression with robust variance was used to estimate prevalence ratios. Any variables showing $p<0.05$ in the multiple model were considered to be associated with the outcome.

Considering that (1) the study population comprised exclusively working mothers with childcare in the workplace, and that (2) providing childcare in the workplace has been pointed out as a powerful strategy to increase the rates of exclusive breastfeeding and reduce pacifier use, for every factor significantly associated with pacifier use, an exploratory analysis was conducted of the prevalence of pacifier use according to child age upon enrollment into the childcare center.

\section{RESULTS}

Of the 100 questionnaires sent out, four were excluded because the children's mothers did not work at the institution at the time the child was born, five were returned blank, and 45 were not returned even after a second deadline request. As a result, the questionnaires answered by 46 mothers were analyzed in the present study.

The prevalence of pacifier use was $63 \%$. Table 1 presents the characteristics of mothers and children participating in the study. Mean child age was 2.6 years, with a predominance of females. Over half of the children had been enrolled into the childcare center before 6 months of age. There were no cases of children with speech/language or anatomic-physiological disorders.

Among the women, most were aged $\geq 35$ years, and none was younger than 20 years. Most mothers had completed higher education and were health professionals. All mothers reported having enjoyed a 120-day maternity leave. At the moment of data collection, all children were bottle-fed. 
Table 1. Profile of mothers and children participating in the study, Marília, 2015

\begin{tabular}{|c|c|c|}
\hline & \multicolumn{2}{|c|}{$\mathrm{N}=46$} \\
\hline & $\mathbf{N}$ & $\%$ \\
\hline \multicolumn{3}{|l|}{ Child gender } \\
\hline Female & 29 & 63.0 \\
\hline Male & 17 & 37.0 \\
\hline \multicolumn{3}{|c|}{ Low birth weight $(\leq 2500 \mathrm{~g})$} \\
\hline Yes & 4 & 8.7 \\
\hline No & 42 & 91.3 \\
\hline \multicolumn{3}{|c|}{ Birth at Baby-Friendly Hospital } \\
\hline Yes & 10 & 21.7 \\
\hline No & 36 & 78.3 \\
\hline \multicolumn{3}{|c|}{ Breastfeeding within first hour of life } \\
\hline Yes & 32 & 71.1 \\
\hline No & 13 & 28.9 \\
\hline \multicolumn{3}{|l|}{ Pacifier use } \\
\hline No & 17 & 37.0 \\
\hline Yes & 29 & 63.0 \\
\hline \multicolumn{3}{|c|}{ Age upon enrollment in the childcare center } \\
\hline$\leq 5.0$ months & 17 & 37.0 \\
\hline 5.1-6.0 months & 10 & 21.7 \\
\hline$>6$ months & 19 & 41.3 \\
\hline \multicolumn{3}{|l|}{ Maternal age } \\
\hline$<35$ years & 22 & 47.8 \\
\hline$\geq 35$ years & 24 & 52.2 \\
\hline \multicolumn{3}{|l|}{ Maternal education } \\
\hline Secondary education & 16 & 24.8 \\
\hline Higher education & 30 & 65.2 \\
\hline \multicolumn{3}{|l|}{ Primiparity } \\
\hline Yes & 28 & 60.9 \\
\hline No & 18 & 38.1 \\
\hline \multicolumn{3}{|l|}{ Health professional } \\
\hline Yes & 34 & 73.9 \\
\hline No & 12 & 26.1 \\
\hline \multicolumn{3}{|l|}{ Breastfeeding breaks } \\
\hline Yes & 5 & 10.8 \\
\hline No & 41 & 89.2 \\
\hline
\end{tabular}

Table 2 presents the age of children upon the introduction of the pacifier, as well as the reasons informed by mothers for introducing the pacifier. Early introduction of the pacifier (i.e., $\leq \mathbf{3 0}$ days of life) was observed in half of the population assessed. The main reasons informed for introducing a pacifier were aspects related to the baby's behavior (cry, sleep, fussiness). Few mothers informed having introduced the pacifier due to their return to work or to their children's enrollment into the childcare center.

Table 2. Age and reasons for pacifier introduction as informed by mothers, Marília, 2015

\begin{tabular}{lcc}
\hline \multirow{2}{*}{ Variable } & \multicolumn{2}{c}{$\mathbf{N}=\mathbf{2 9}^{*}$} \\
\cline { 2 - 3 } & $\mathbf{N}$ & $\mathbf{\%}$ \\
\hline Age upon pacifier introduction & 10 & 35.7 \\
$\leq 15$ days & 4 & 14.3 \\
16-30 days & 3 & 10.7 \\
$31-60$ days & 2 & 7.1 \\
$61-90$ days & 2 & 7.1 \\
$91-120$ days & 3 & 10.7 \\
$121-150$ days & 4 & 14.3 \\
$>150$ days & & \\
\hline Reason for pacifier introduction & 8 & 27.6 \\
Helps at sleep time & 20 & 69.0 \\
Soothes the baby & 3 & 10.3 \\
Mother's return to work & 4 & 13.8 \\
Other people taking care of the baby & 3 & 6.9 \\
Baby started to suck finger & 3 & 10.3 \\
Other**
\end{tabular}

*Number of mothers who reported pacifier introduction.

**0ther reasons: child took everything to mouth; child had too much colic. 
Figure 1 shows rates of pacifier use according to age at the moment of pacifier introduction and age upon enrollment into the childcare center. Mean age upon pacifier introduction among the children enrolled into the childcare center before 5 months of age was 92.3 days (median=60days); for those enrolled at 5.1-6.0 months, the mean was 67.5 days (median $=52.5$ days); and for those enrolled after 6 months of age, the mean was 74.1 days (median $=30$ days). No statistically significant differences were observed between the categories analyzed ( $p=0.30$; chi-square). However, pacifier introduction at 120 and 150 days of life, which is the approximate time of the mother's return to work, was more frequent among the children enrolled into childcare after 6 months of age.

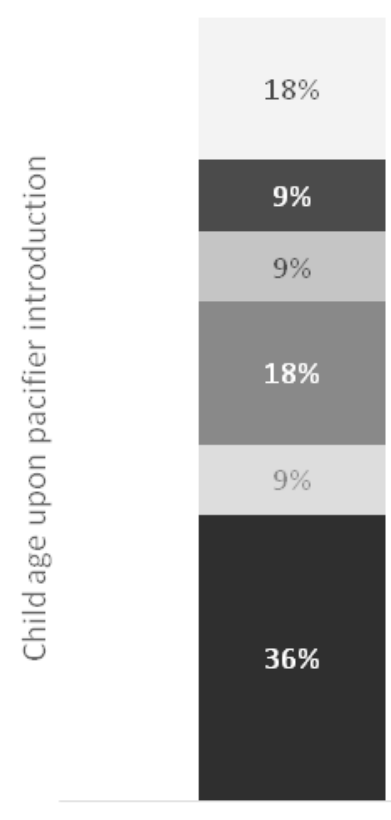

$\leq 5.0$ months

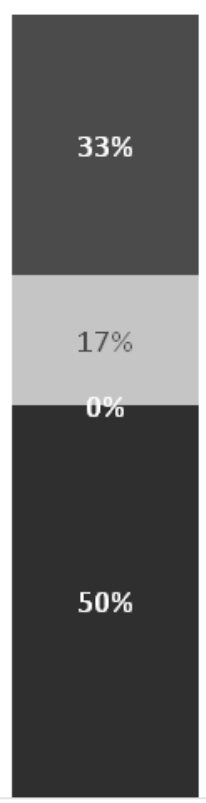

5.1-6.0 months

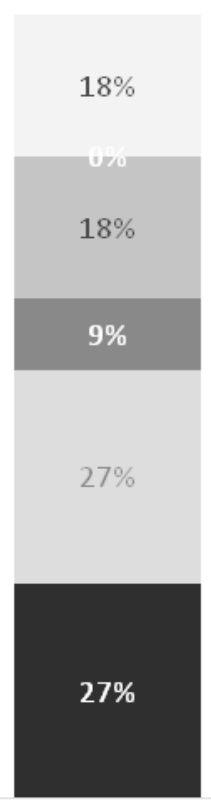

6.1-24.0 months

Child age upon enrollment into childcare center

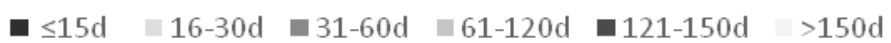

Figure 1. Child age at the moment of pacifier introduction according to age upon enrollment in the childcare center, Marilia, 2015 
Table 3 describes associations between pacifier use and the variables investigated. The only variable that remained independently associated with pacifier use in children of mothers with childcare in the workplace was maternal education. Lower maternal education (secondary education), in this population, was a protective factor against pacifier use.

Table 3. Factors associated with pacifier use in children of working women with childcare center in the workplace (poisson multiple regression analysis), Marília, 2015

\begin{tabular}{|c|c|c|c|c|}
\hline & \multicolumn{2}{|c|}{ Pacifier use } & \multirow{2}{*}{$\begin{array}{c}\text { Adjusted } \\
\text { prevalence ratio }\end{array}$} & \multirow{2}{*}{$\mathbf{p}^{*}$} \\
\hline & $\mathbf{N}$ & $\%$ & & \\
\hline \multicolumn{5}{|l|}{ Child gender } \\
\hline Female & 20 & 69.0 & 1 & \multirow{2}{*}{0.323} \\
\hline Male & 9 & 31.0 & $0.77[0.46-1.29]$ & \\
\hline \multicolumn{5}{|l|}{ Low birth weight $(\leq 2500 \mathrm{~g})$} \\
\hline No & 26 & 89.7 & 1 & \multirow{2}{*}{0.508} \\
\hline Yes & 3 & 10.3 & $1.26[0.63-2.52]$ & \\
\hline \multicolumn{5}{|c|}{ Birth at Baby-Friendly Hospital } \\
\hline Yes & 5 & 17.2 & 1 & \multirow{2}{*}{0.718} \\
\hline No & 24 & 82.8 & $0.92[0.57-1.48]$ & \\
\hline \multicolumn{5}{|c|}{ Breastfeeding within first hour of life } \\
\hline Yes & 21 & 72.4 & 1 & \multirow{2}{*}{0.752} \\
\hline No & 8 & 27.6 & $0.88[0.44-1.74]$ & \\
\hline \multicolumn{5}{|c|}{$\begin{array}{l}\text { Age upon enrollment in the childcare } \\
\text { center }\end{array}$} \\
\hline$\leq 5.0$ months & 12 & 41.4 & 1 & \\
\hline 5.1-6.0 months & 6 & 20.7 & $0.82[0.50-1.32]$ & 0.504 \\
\hline$>6$ months & 11 & 37.9 & $1.07[0.65-1.76]$ & 0.655 \\
\hline \multicolumn{5}{|l|}{ Maternal age } \\
\hline$<35$ years & 13 & 44.8 & 1 & \multirow[b]{2}{*}{0.545} \\
\hline$\geq 35$ years & 16 & 55.2 & $1.18[0.69-1.99]$ & \\
\hline \multicolumn{5}{|l|}{ Maternal education } \\
\hline Higher education & 23 & 79.1 & 1 & \multirow{2}{*}{$0.031^{* *}$} \\
\hline Secondary education & 6 & 20.7 & $0.47[0.23-0.93]$ & \\
\hline \multicolumn{5}{|l|}{ Primiparity } \\
\hline Yes & 12 & 41.4 & 1 & \multirow[b]{2}{*}{0.875} \\
\hline No & 17 & 58.6 & $0.96[0.60-1.54]$ & \\
\hline \multicolumn{5}{|l|}{ Health professional } \\
\hline Yes & 21 & 72.4 & 1 & \multirow{2}{*}{0.456} \\
\hline No & 8 & 27.6 & $1.18[0.75-1.84]$ & \\
\hline \multicolumn{5}{|l|}{ Breastfeeding breaks } \\
\hline Yes & 2 & 6.9 & 1 & \multirow{2}{*}{0.368} \\
\hline No & 27 & 93.1 & $1.66[0.55-5.03]$ & \\
\hline
\end{tabular}

* Significance level in Poisson multiple regression analysis.

$* * p<0.05$. 
As seen in Figure 2, regardless of child age upon enrollment into the childcare center, pacifier use was more frequent among children of mothers with higher education $(p=0.03)$. Among the children enrolled into the childcare center before 6 months of life, virtually all the children who used a pacifier had mothers with higher education.

\section{- Higher education \\ Secondary education}

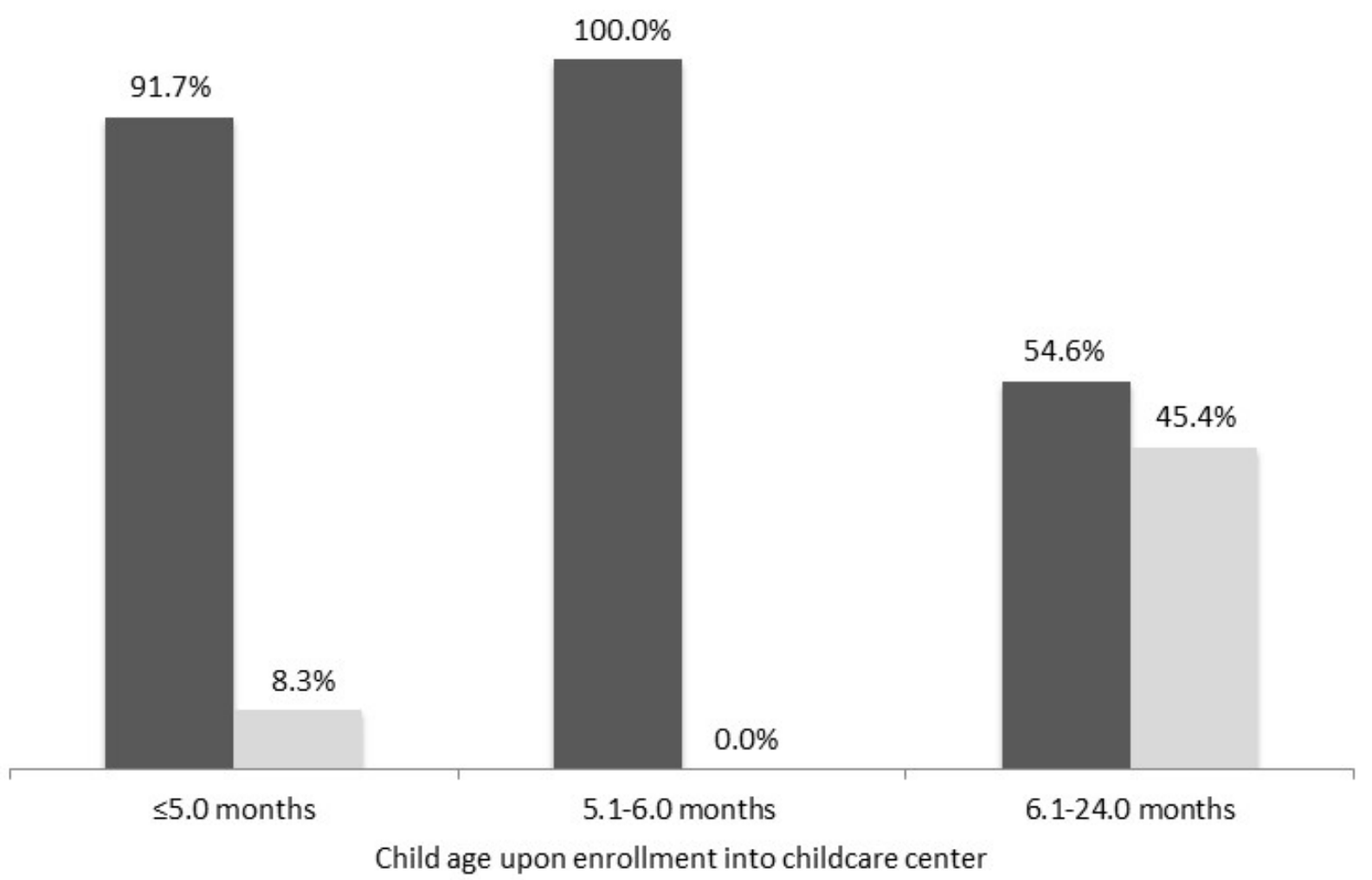

Figure 2. Pacifier use according to maternal education and age upon enrollment in the childcare center, Marilia, 2015

\section{DISCUSSION}

To the authors' knowledge, this is the first study designed to analyze pacifier use among children of women with childcare center in the workplace. A high prevalence of pacifier use was observed, as well as early pacifier introduction. Maternal education was the only factor independently associated with pacifier use in this sample. The peculiar characteristics of this population should be taken into consideration when planning and implementing preventive health strategies in the context of infant education, especially in childcare centers available in the workplace.

The prevalence of pacifier use identified in this study was higher than the national rate of $42.6 \%$ identified among infants younger than 1 year assessed in the previously mentioned 2009 nation-wide survey ${ }^{16}$. Also, another study involving working women found a prevalence of $43.5 \%$ of pacifier use among infants younger than 1 year $^{22}$. High rates of pacifier use, ranging from 43.5 to $80 \%$, have been reported in children attending childcare centers ${ }^{22,27,28}$. Variations in the prevalence of pacifier use in different populations may be related to socioeconomic and cultural aspects $^{17,21}$.

Early pacifier introduction (i.e., in the first month of life) was frequent among the children of working women with childcare in the workplace analyzed in the present study. Other Brazilian studies with similar populations corroborate this finding, 19,29-32. Early pacifier introduction is associated with early interruption of exclusive breastfeeding ${ }^{9-11,18}$. In this sense, there is evidence suggesting that women participating in breastfeeding promotion programs that include information about the influence of pacifier use on child health are less likely 
to use the device ${ }^{19}$; indeed, in that study, pacifier introduction in the first month of life was much lower than in the present sample (13.3 vs. $50.0 \%$ ). Even though few studies have investigated the timing of pacifier introduction, this information is extremely important, as it may determine the frequency, intensity, and persistence of the habit in early childhood ${ }^{10}$.

The most frequent reasons for introducing a pacifier as reported by the mothers assessed were "to soothe the baby," followed by "to help at sleep time." These findings demonstrate the naturalization of the soothing effect associated with pacifiers, as evidenced in qualitative studies on the topic ${ }^{21,24,33}$. Even though working outside the home was not the main cause of pacifier introduction in the population assessed, analysis of populational data in Brazil has revealed that the mother's return to work is one of the factors associated with exclusive pacifier use(i.e., using a pacifier but not using a bottle or other artificial teats) among infants younger than 1 year $^{17}$. In this sense, the mother's return to work may not be a primary cause for pacifier introduction, but it may strengthen its use. Future analyses are warranted to confirm this hypothesis.

This was the first time that low maternal education was identified as a protective factor against pacifier use, in contrast with previous studies ${ }^{34-39}$. This discrepancy may reflect two peculiarities of the population assessed, namely: (1) all mothers were health professionals; and (2) all had completed at least secondary education ( $>8$ years of formal education). In this sense, these findings should be considered a tolerant and perhaps underestimated view of the implications of pacifier use in terms of child health and breastfeeding, even among mothers working in the health sector ${ }^{40}$. Further studies involving working women with childcare in the workplace are needed before we can achieve a better understanding of the relationship between pacifier use and lower maternal education, if possible considering child age upon enrollment into childcare. Also in contrast with the literature ${ }^{17,19}$,the other factors assessed were not associated with pacifier use, further underscoring the singularity of this population and the importance of conducting more studies with working mothers who have childcare available in the workplace.

The results here presented expand the current knowledge on factors associated with pacifier use among working women with childcare in the workplace. One limitation of our data analysis was the impossibility of exploring the relationship between pacifier use and bottle feeding, as the whole sample was bottle fed. Another limitation is related to our high rate of non-responders, urging caution in generalizing the findings. Still, exploratory studies are important to raise hypotheses and essential to advance scientific knowledge.

The implementation of childcare centers in the workplace has been designed as a strategy to promote, protect, and support breastfeeding among women in formal employment. Early pacifier introduction and the consequences of this practice for breastfeeding and child health make this topic a top priority in the scenario of infant education. In this sense, based on the results observed, some measures could help working women maintain breastfeeding and avoid the use of a pacifier, e.g.: (1) expanding the number of vacancies in childcare centers so as to provide the service to all female employees in each company; (2) developing pro-breastfeeding actions, such as encouraging the use of cups and offering expressed breast milk; (3) developing educational actions aimed at parents and continued education activities for caretakers addressing the pros and cons of pacifier use for child health, including alternative ways to soothe infants without the use of artificial nipples; and(4) establishing institutional guidelines about the use of pacifiers and strategies to avoid its constant use in the childcare setting.

When working with infants, the main challenge of school teams in general and of speech therapists in particular is the adoption of strategies that will encourage the maintenance of exclusive breastfeeding, as well as preventive measures against the use of pacifiers during the time the child remains in childcare. Further research involving working women with childcare in the workplace is warranted to corroborate the exploratory findings of this study.

\section{CONCLUSION}

A high prevalence of pacifier use was observed, as well as early pacifier introduction, among children of working women with childcare in the workplace. Of the factors assessed, lower maternal education was associated with the outcome, acting as a protective factor against pacifier use in this population.

\section{REFERENCES}

1. Sexton $S$, Natale R. Risks and benefits of pacifiers. Am Fam Physician. 2009;79(8):681-5.

2. Lubianca Neto JF, Hemb L, Silva DB. Systematic literature review of modifiable risk factors for 
recurrent acute otitis media in childhood. J Pediatr. 2006;82(2):87-96.

3. Goes EG, Ribeiro-Junior HC, Vale MP, Paiva SM, Serra-Negra JM, Ramos-Jorge ML et al. Influence of nonnutritive sucking habits, breathing pattern and adenoid size on the development of malocclusion. Angle Orthod. 2008;78(4)647-54.

4. Castilho SD, Rocha MAM. Uso de chupeta: história e visão multidisciplinar. J Pediatr. 2009;85(6):480-9.

5. Veron HL, Antunes AG, Milanesi JM, Corrêa ECR. Implications of mouth breathing on the pulmonary function and respiratory muscles. Rev CEFAC. 2016;18(1):242-51.

6. Felcar JM, Bueno IR, Massan AS, Torezan RP, Cardoso JR. Prevalence of mouth breathing in children from an elementary school. Ciên Saúde Coletiva. 2010;15(2):437-44.

7. Neiva FCB, Cattoni DM, Ramos JLA, Issler H. Early weaning: implications to oral motor development. J Pediatr. 2003;79(1):7-12.

8. Shotts LL, McDaniel DM, Neeley RA. The impact of prolonged pacifier use on speech articulation: a preliminary investigation. CICSD. 2008;35(Spring):72-5.

9. Barbosa MB, Palma D, Domene SMA, Taddei JAAC, Lopez FA. Fatores de risco associados ao desmame precoce e ao período de desmame em lactentes matriculados em creches. Rev Paul Pediatr. 2009;27(3):272-81.

10. Buccini GS, Pérez-Escamilla R, Paulino LM, Araújo $\mathrm{CL}$, Venancio SI. Pacifier use and interruption of exclusive breastfeeding: Systematic review and meta-analysis. Matern Child Nutr. 2017;13(3). doi: 10.1111/mcn.12384.

11. Buccini GS, Perez-Escamilla R, Venancio SI. Pacifier use and Exclusive Breastfeeding in Brazil. J Hum Lact. 2015;32(3):52-60.

12. Roig AO, Martínez MR, Garcia JC, Hoyos SP, Navidad GL, Álvarez JCF et al. Factors associated to breastfeeding cessation before 6 months. Rev Latino-Am Enfermagem. 2010;18(3):373-80.

13. Vogel AM, Hutchison BL, Mitchell EA. The impact of pacifier use on breastfeeding: A prospective cohort study. J Paediatr Child Health. 2001;37(1):58-63.

14. Howard CR, Howard FM, Lanphear B, deBlieck EA, Eberly S, Lawrence RA. The effects of early pacifier use on breastfeeding duration. Pediatrics. 1999;103(3):1-6.

15. World Health Organization [WHO]. Indicators for Assessing Infant and Young Child Feeding
Practices: Conclusions of a Consensus Meeting Held 6-8 November 2007 in Washington, DC, USA. Geneva: 2008.

16. Brasil. Ministério da Saúde. Secretaria de Atenção à Saúde, Departamento de Ações Programáticas e Estratégicas. II Pesquisa de Prevalência de Aleitamento Materno nas Capitais Brasileiras e Distrito Federal. Série C. Projetos, Programas e Relatórios. Brasília - DF: 2009.

17. Buccini GS, Benício MDD, Venancio SI. Determinants of using pacifier and bottle feeding. Rev Saúde Pública. 2014;48(4):571-85.

18. Mascarenhas MLW, Albernaz EP, Silva MB, Silveira RB. Prevalence of exclusive breastfeeding and its determiners in the first 3 months of life in the South of Brazil. J Pediatr. 2006;82(4):289-94.

19. Carrascoza KC, Possobon RF, Ambrosano GMB, Costa Junior AL, Moraes ABA. Determinants of pacifier use among infants attending an interdisciplinary breastfeeding promotion program. Rev CEFAC. 2014;16(2):582-91.

20. Dadalto ECV, Rosa EM. Factors associated to pacifier use in preterm infants. Rev CEFAC. 2016;18(3):601-12.

21. Sertório SCM, Silva IA. The symbolic and utilitarian facets of pacifiers according to mothers. Rev Saúde Pública.2005;39(2):156-62.

22. Brasileiro AA, Ambrosano GMB, Marba STM, Possobon RF. Breastfeeding among children of women workers. Rev Saúde Pública. 2012;26(4):642-8.

23. Mauch CE, Scott JA, Magarey AM, Daniels LA. Predictors of and reasons for pacifier use in first-time mothers: an observational study. BMC Pediatr. 2012;12(7):1-10

24. Victora CG, Behague DP, Barros FC, Olinto MTA, Weiderpass, E. Pacifier use and short breastfeeding duration: cause, consequence, or coincidence? Pediatrics. 1997;99(3):445-53.

25. Rea MF, Venâncio SI, Batista LE, Santos RG, Greiner T. Possibilities and limitations of breastfeeding among women in formal employment. Rev Saúde Pública. 1997;31(2):149-56.

26. Abdulwadud OA, Snow ME. Interventions in the workplace to support breastfeeding for women in employment. Cochrane Database of Systematic Reviews 2012, Issue 10. Art. No.: CD006177. DOI: 10.1002/14651858.CD006177.pub3).

27. Warkentin S, Viana KJ, Zapana PM, Taddei JAA. Factors associated with the interruption of exclusive 
breastfeeding before six months for children enrolled in public and philanthropic daycare centers in Sao Paulo. Nutrire Rev Soc Bras Aliment Nutr. 2012;37(2):105-17.

28. Souza MHN, Sodrê VRD, Silva FNFS. Prevalence and factors associated with breastfeeding for children attending a public communitarian child daycare center. Cien Enferm. 2015;21(1):55-67.

29. Espirito-Santo LC, Oliveira LD, Giugliani ER. Factors associated with low incidence of exclusive breastfeeding for the first 6 months. Birth. 2007;34(3):212-9.

30. Vieira TO, Vieira GO, Oliveira NF, Mendes CMC, Giugliani ERJ. Duration of exclusive breastfeeding in Brazilian population: new determinants in a cohort study. BMC Pregnancy Childbirth. 2014;14(175):1-9.

31. Cunha AJ, Leite AM, Machado MM. Breastfeeding and pacifier use in Brazil. Indian J Pediatr. 2005; 72(3):209-12.

32. Sanches MTC, Buccini GS, Gimeno SGA, Rosa TEC, Bonamigo AW. Factors associated with interruption of exclusive breastfeeding in low birth weight infants receiving primary care. Cad Saúde Pública. 2011;27(5):953-65.

33. Dadalto ECV, Rosa EM. Cultural aspects of offering pacifier to children. Rev Bras Crescimento Desenvolv Hum. 2013;23(2):231-37.

34. Barros FC, Victora CG, Semer TC, Tonioli SF, Tomasi E, Weiderpass E. Use of pacifiers is associated with decreased breast-feeding duration. Pediatrics. 1995;95(4):497-9.

35. Hörnell A, Aarts C, Kylberg E, Hofvander Y, GebreMedhin M. Breastfeeding patterns in exclusively breastfed infants: A longitudinal prospective study in Uppsala, Sweden. Acta Paediatr. 1999;88(2):203-11.

36. North K, Fleming P, Golding J, the ALSPAC study team. Pacifier use and morbidity in the first six months of life. Pediatrics. 1999;103(3):1-7.

37. North SK, Fleming P, Golding J. Socio-demographic associations with digit and pacifier sucking at 15 months of age and possible associations with infant infection. The ALSPAC Study Team. Avon longitudinal study of pregnancy and childhood. Early Hum Dev. 2000;60(2):137-48.

38. Pinto MCGL, Melo GFB, Colares V, Katz CRT. Social, economic and cultural factors associated with pacifier use in children from birth to 4 years-of-age, in Recife, Pernambuco, Brazil. Arq Odontol. 2003;39(4):285-96.

39. Soares MEM, Giugliani ERJ, Braun ML, Salgado ACN, Oliveira AP, Aguiar PR. Pacifier use and its relationship with early weaning in infants born at a Child-Friendly Hospital. J Pediatr. 2003;79(4):309-16.

40. Lamoynier JA. The influence of nipples and pacifiers on breastfeeding duration. $J$ Pediatr.2003;79(4):284-86. 